\title{
İnsülin Enjeksiyonu Uygulamalarında Enjeksiyon Bölgesinin Mikrobiyal Yükünün İncelenmesi ${ }^{*}$
}

\author{
Dilek YILMAZ ${ }^{1}$, Perihan ERKAN ALKAN², Cüneyt ÖZAKIN ${ }^{3}$, Gülsev DİRÍK ${ }^{4}$
}

1 Bursa Uludağ Üniversitesi Sağlık Bilimleri Fakültesi, Hemşirelik Esasları Anabilim Dalı, Bursa.

2 Bursa Uludağ Üniversitesi Sağlık Hizmetleri Meslek Yüksekokulu, Tıbbi Laboratuvar Teknikleri Programı, Bursa.

3 Bursa Uludağ Üniversitesi Tıp Fakültesi, Tıbbi Mikrobiyoloji Anabilim Dalı, Bursa.

4 Bursa Uludağ Üniversitesi, Sağlık Uygulama ve Araştırma Merkezi, Endokrinoloji ve Metabolizma Hastalıkları Kliniğgi, Bursa.

\section{ÖZET}

Bu çalışmada; insülin enjeksiyonu öncesi enjeksiyon bölgesindeki mikrobiyal yük incelenerek deri antisepsisi için \%70’lik etil alkol kullanımının gerekli olup olmadığını değerlendirmek amaçlandı. Araştırma, bir üniversite hastanesinin Endokrinoloji ve Metabolizma Hastalıkları Kliniğinde yürütüldü. Araştırmanın örneklemini; Tip 1 Diabetes Mellitus (DM) tanısı alan, insülin tedavisi uygulanan, enjeksiyon bölgesi belirgin derecede kirli olmayan, enfeksiyon riski bulunmayan ve araştırmaya katılmayı gönüllü kabul eden 66 hasta oluşturdu. İnsülin enjeksiyonları abdominal bölgeye uygulandı ve her hastadan toplam iki kez cilt kültürü alındı. İnsülin enjeksiyonu öncesi hastanın enjeksiyon bölgesinde $10 \mathrm{~cm}^{2}$ olarak belirlenmiş bir alan steril bir eküvyon ile deneyimli bir araştırmacı tarafından cilt üzerine sürtülerek ilk kültür örneği alındı. Daha sonra bölge \%70'lik etil alkol emdirilmiş pamuk ile içten dıșa doğru silindi ve alkolün kuruması için 30 saniye beklendi. Ardından hastaya insülin enjeksiyonu uygulandı ve aynı bölgeden ikinci kültür örneği alındı. Araştırmaya katılan hastaların \%95'inde enjeksiyon öncesi, \%66.7'sinde ise enjeksiyon sonrası enjeksiyon bölgesinde üreme olduğu saptandı. Enjeksiyon öncesi enjeksiyon bölgesi üzerindeki $\mathrm{cm}^{2}$ bașına ortalama Colony Forming Unit (CFU) $60.13 \pm 51.65, \% 70$ 'lik etil alkol kullandıktan sonraki ortalama CFU $15.98 \pm 25.27$ olarak belirlendi ve bu istatistiksel olarak anlamlı ölçüde yüksek bulundu ( $\mathrm{p}=0.000)$. Araştırma sonucunda; Endokrinoloji ve Metabolizma Hastalıkları Kliniğinde Tip 1 DM tanısı ile yatan hastalara insülin enjeksiyonu öncesi cilt antisepsisinin gerekli olduğu kanısına varıldı.

Anahtar Kelimeler: Cilt hazırlığı. Deri antisepsisi. İnsülin enjeksiyonu. \%70’lik etil alkol.

Determination of Microbial Load of Injection Site in Insulin Injections

\begin{abstract}
In this study, it was aimed to evaluate whether the use of $70 \%$ ethyl alcohol for skin antisepsis is necessary by examining the microbial load at the injection site before the injection of insulin. The study was conducted at Clinic of Endocrinology and Metabolic Diseases of an university hospital. The sample of the study consisted of 66 patients who were diagnosed with Type 1 Diabetes Mellitus (DM), were treated with insulin, had no significant dirt at the injection site, and had no risk of infection and who accepted voluntary participation in the study. Insulin injections were applied to the abdominal region and a total of two skin cultures were obtained from each patient. The first culture sample was obtained by rubbing a 5-6 $\mathrm{cm}^{2}$ area on the skin which was determined before insulin injection with a sterile swab by an experienced researcher. The area was then wiped out from inside with $70 \%$ ethyl alcohol impregnated cotton, and the alcohol was allowed to dry for 30 seconds. The patient was then given insulin injection and a second culture sample was obtained from the same site. Microbial growth was found in $95 \%$ of the patients before injection and in $66.7 \%$ of the patients after the injection. The mean Colony Forming Unit (CFU) was $60.13 \pm 51.65$ per $\mathrm{cm} 2$ on the injection site before injection, the mean CFU $15.98 \pm 25.27$ after using $70 \%$ ethyl alcohol and this was determined as statistically significantly higher $(p=0.000)$. As a result of the research; for the patients with Type 1 DM in the Clinic of Endocrinology and Metabolic Diseases, before the injection of insulin the skin antisepsis was considered to be necessary.
\end{abstract}

Key Words: Skin preparation. Skin antisepsis. Insulin injection. $\mathbf{7 0 \%}$ ethyl alcohol.

Geliş Tarihi: 05 Kasım 2018

Kabul Tarihi: 05 Şubat 2018

* Hastane İnfeksiyonları Kongresi 2018'de (04-08 Nisan 2018, Antalya) Poster bildiri olarak sunulmuştur.

Dr. Dilek YILMAZ

Bursa Uludağ Üniversitesi,

Sağlık Bilimleri Fakültesi,

Hemşirelik Esasları Anabilim Dalı,

Bursa

Tel.: 02242942454

E-posta: dilekk@uludag.edu.tr
Enjeksiyonlar, dünya genelinde sağlık çalışanları tarafindan kullanılan en yaygın prosedürler arasında$\mathrm{d}_{\mathrm{r}} \mathrm{r}^{1,2}$. Özellikle subkutan insülin enjeksiyonları, hem klinik ortamlarda sağlık profesyonelleri tarafindan hem de kendi kendine uygulama zorunluluğu nedeniyle hastalar tarafından bireysel olarak gerçekleștirilen ve parenteral ilaç uygulamaları içinde önemli yer tutan bir girişimdir ${ }^{3-5}$. Subkutan insülin enjeksiyon ile ilgili hatalı uygulamalar, insülin regülasyonunu olumsuz 


\section{Yılmaz, ark.}

yönde etkilediği kadar istenmeyen sonuçlara da neden olmaktadır ${ }^{3}$. Bu nedenle insülin enjeksiyonlarını doğru enjeksiyon tekniği ile uygulamak ve hastaları bu doğrultuda eğitmek başta hemşireler olmak üzere sağlik profesyonellerinin temel sorumlulukları arasında yer almaktadir ${ }^{6}$.

Diabetes Mellitus (DM), insülin salınımının tam ya da kısmi eksikliği veya değişik derecelerdeki insülin direnci sonucunda karbonhidrat, yağ ve protein metabolizmasının bozukluğuyla seyreden, makrovasküler ve mikrovasküler komplikasyonların oluştuğu kronik ve metabolik bir hastalıktır ${ }^{7}$. Dünya Sağlık Örgütü (DSÖ) ve Uluslararası Diyabet Federasyonu varsayımlarına göre tüm yaş grupları dikkate alındığında dünyada 930.000 civarında Tip 1 DM'li hastanın bulunduğu ve prevelansın yaklaşık \%0,05 olduğu sanılmaktadır ${ }^{8,9}$. DM tedavisinde amaç, kan glikoz seviyesini kontrol altında tutmaktır. Tip $1 \mathrm{DM}$ varlığında yaşam boyunca, Tip 2 DM ise sıklıkla hastalığın seyrinin kontrolü ve komplikasyonlarının azaltılması amacıyla, bireylerin yaklaşık \%40'ına insülin tedavisi planlanmaktadır ${ }^{3,10}$.

Etkili diyabet yönetiminde insülinin subkutan enjeksiyon yöntemi ile uygulanması, istenmeyen etkilerin önlenmesi/azaltılması adına önem taşımaktadır ${ }^{3,10,11}$. $\mathrm{Bu}$ nedenle, sağlık profesyonellerinin ve diyabetli hastaların; insülin enjeksiyon uygulamalarında yeni gelişmelerle ilgili olarak eğitilmeleri gereklidir ${ }^{12}$. Yapılan farklı çalışmalarda diyabetli bireylerin ve sağlık profesyonellerinin; insülin enjeksiyon tekniği ve cilt hazırlığına yönelik hatalar yaptığı belirlenmiştir $^{9,12-16}$. Yakın bir zamanda Hindistanda yapılan bir çalışmada da insülin kullanıcıların \%72.42'si insülin enjeksiyonu öncesi cilt hazırlığı yapmadığı bildirilmiştir ${ }^{17}$.

Diğer yandan son 30 yıldır yapılan araştırmalar enjeksiyon öncesi cilt antisepsisinin gerekliliği üzerine odaklanmıştı1 ${ }^{18}$. DSÖ tarafından yapılan açıklamaya göre; cilt altı dokuya verilen insülin enjeksiyonlarından önce rutin olarak kullanılan \%70'lik etil alkol ile yapılan deri antisepsisine gerek olmadığı bildirilmiştir ${ }^{2,19,20}$. Ayrıca Türk Diyabet Hemşireleri Derneği de insülin enjeksiyonu öncesi, enjeksiyon bölgesi temiz olduğu durumlarda bölgenin alkol yada farklı antiseptik madde ile temizlenmesinin gerekli olmadığını belirtmiştir ${ }^{21}$. Konuyla ilgili yapılan farklı çalışmalar da enjeksiyon bölgesi kirli olmayan hastaların, intradermal ve subkutan enjeksiyonlarından önce alkol ile yapılan deri hazırlığına gereksinim olmadığını vurgulamışlardır ${ }^{20,22-26}$. Diğer yandan, Kuzu (1999)'nun yaptığı sistematik derleme çalışmasında da subkutan enjeksiyon uygulamaları öncesi deri hazırlığında isopropyl alkol kullanılmasının kanamayı teşvik ettiği ve ekimoz gelişme olasılığını arttırdığ 1 ifade edilmiştir ${ }^{27}$.

Sağlık profesyonellerinin ve hastaların, antiseptik madde uygulamadan enjeksiyon uygulamasını kabul etmeleri arasında genel bir isteksizlik olduğu bildiril- mektedir ${ }^{2,28}$. Dolayısıyla klinik alanda insülin enjeksiyon uygulamaları öncesinde standart bir girişim basamağ 1 olarak sıklıkla yapılan deri antisepsisinin gerekliliği son yıllarda farklı yorumlara açık hale gelmiştir. İnsülin enjeksiyonun sık uygulandığı Endokrinoloji ve Metabolizma Hastalıkları Kliniğinde çalışan hemşirelerin, hastaların enjeksiyon bölgelerinde enfeksiyon açısından bulaş riski bulunmadığı halde sıklıkla \%70'lik etil alkol ile cilt hazırlığı yaptıkları gözlenmiştir. $\mathrm{Bu}$ doğrultuda insülin enjeksiyonu öncesi deri antisepsisinin gerekli olup olmadığını bölgedeki mikrobiyolojik yükü ölçerek bu araştırmanın yapılmasına ihtiyaç duyulmuştur. Çalışmada; insülin enjeksiyonu öncesi enjeksiyon bölgesindeki mikrobiyal yük incelenerek deri antisepsisi için \%70'lik etil alkol kullanımının gerekli olup olmadığını değerlendirmek amaçlanmıştır.

\section{Gereç ve Yöntem}

Yarı deneysel olarak planlanan bu araştırma, Haziran 2017- Aralı 2017 tarihleri arasında bir üniversite hastanesinin Endokrinoloji ve Metabolizma Hastalıkları Kliniğinde yürütüldü. Araştırmanın örneklemini; Tip 1 Diabetes Mellitus (DM) tanısı alan, hekim tarafından insülin tedavi istemi yapılan, enjeksiyon bölgesi gözle görülecek düzeyde kirli olmayan, enfeksiyon riski bulunmayan ve araştırmaya katılmayı gönüllü kabul eden 66 hasta oluşturdu. Örneklemin büyüklüğü istatistiksel olarak Güç Analizi (Power Analysis) ile hesapland1.

\section{Verilerin Toplanmast}

Araştırma grubuna dahil edilen hastaların onamları alındıktan sonra, hastaların tanıtıcı bilgileri "Veri Toplama Formu”na kaydedildi. Araştırma kapsamına alınan her bir hastaya araştırmacı tarafından sadece bir kez insülin enjeksiyonu uyguland. Tüm enjeksiyonlar; çalışmanın yapıldığı kliniğin prosedürü gereği; hazır kalem enjektörüyle değil de normal insulin enjektörüyle uyguland1. Literatürde; insülin enjeksiyonları için en güvenli bölge abdominal bölge olduğu bildirilmesi nedeni ile enjeksiyonlar her bir hastanın sağ veya sol abdominal bölgesine yapıldd1,6,27,29,30. Herbir hastaya aynı insülin enjeksiyonu protokolü uygulandi $^{31}$ (Tablo I).

İnsülin enjeksiyonu öncesi alanda uzmanlığı bulunan bir araştırmacı, hastanın enjeksiyon bölgesinde $10 \mathrm{~cm}^{2}$ olarak belirlenen alandaki cilt üzerine steril bir eküvyonu sürterek ${ }^{22,23,26,32}$ ilk kültür örneğini aldı. Daha sonra bölge, \%70'lik etil alkol emdirilmiş pamuk ile içten dışa doğru silindi ve alkolün kuruması için 30 saniye beklenildi ${ }^{2,19,28}$. Ardından hastaya insülin enjeksiyonu uygulandı ve aynı bölgeden ikinci kültür örneği alındı. Transport besiyeri içine daldırılan eküvyonlar bekletilmeden laboratuvara götürülerek semi- 


\section{İnsülin Enjeksiyon Bölgesinin Mikrobiyal Yükü}

kantitatif kültür yöntemi ile kanlı agar besiyerine ekildi. Kültür plakları $37{ }^{\circ} \mathrm{C}$ 'de inkübe edilerek 24 saat sonra değerlendirildi. İnkübasyon sonrası değerlendirmede $15 \mathrm{CFU}$ üreme saptanması anlamlı olarak kabul edildi.

Tablo I. İnsülin Enjeksiyonu Uygulama Protokolü

Uygun dozda insülin enjektöre çekildikten sonra enjektöre 0.2$0.3 \mathrm{ml}$ hava eklenerek hava kilidi tekniği uygulandı.

Bireyin supine pozisyonunda olması sağlandı.

Uygulama yapılacak bölge gözlenerek ve palpe edilerek değerlendirildi.

*Eldiven giyildi.

Abdominal bölge umblikustan geçen dikey ve yatay çizgiyle dörde bölündü. Çizgiler arasında kalan bölgelere umblikus çevresinden 5-6 $\mathrm{cm}^{2}$ lik uzaklıkta uygun alan seçildi.

İğnenin koruyucusu çıkarıldı. Aktif elin baş ve işaret parmakları arasında enjektör tutuldu.

Diğer el ile belirlenen alanın her iki yanından subkutan doku kavrandı.

İğnenin keskin ucu yukarı bakacak şekilde dokuya 450'lik açıyla seri şekilde girildi.

Kavranan doku insülin verme işlemi bitene kadar bırakılmadı.

İnsülin verme işlemi bittikten sonra iğneyi geri çekmeden önce 5-10 saniye beklenildi.

Giriş açısını bozmayacak şekilde iğne seri bir şekilde çekilerek kuru pamukla bölgeye basınç uygulandı.

* Uygulayıcının elindeki florada bulunan mikroorganizmaların enjeksiyon bölgesine geçişini engellemek için giyilmiştir.

\section{Etik Boyutu}

Araştırmanın yürütülebilmesi için çalışmanın yapıldığı kurumun Tıp Fakültesi Klinik Araştırmalar Etik Kurulu'ndan (Karar No: 2017-8/20) onay ve araştırmanın yapıldığı kurumdan yasal izinler alındı. Ayrıca araştırmaya katılan hastalardan da bilgilendirilmiş onam alındi.

\section{Istatistiksel Analiz}

Araştırma verilerinin değerlendirilmesi Statistical Package For Social Science (SPSS) 22.0 paket programı kullanılarak yapıldı. Verilerin analizinde sayı, yüzde, ortalama ile verilerin normal dağılım göstermemesi nedeniyle Wilcoxon $\mathrm{T}$ testi kullanıldı. İstatistiksel anlamlılık değeri $\mathrm{p}<0.05$ olarak kabul edildi.

\section{Bulgular}

Araştırmaya katılan hastaların bazı tanıtıcı özellikleri Tablo II'de verilmiştir. Buna göre; hastaların \%65.2'si kadın, yaş ortalamalarının $53.87 \pm 13.71$ yıl, enjeksiyon uygulama bölgesinin ise \%54.5'inin sağ abdominal bölge olduğu bulundu.
Tablo II. Araştırmaya Katılan Hastaların Bazı Tanıtıc1 Özellikleri $(n=66)$

\begin{tabular}{|c|c|c|}
\hline \multicolumn{3}{|l|}{ Değişkenler } \\
\hline Yaş (X土SS) yıl & \multicolumn{2}{|c|}{$53.87 \pm 13.71 \mathrm{yll}$} \\
\hline Cinsiyet & $\mathrm{n}$ & $\%$ \\
\hline Kadın & 43 & 65.2 \\
\hline Erkek & 23 & 34.8 \\
\hline \multicolumn{3}{|c|}{ Enjeksiyon Uygulama Bölgesi } \\
\hline Sağ Abdominal Bölge & 36 & 54.5 \\
\hline Sol Abdominal Bölge & 30 & 45.5 \\
\hline
\end{tabular}

$\mathrm{X}$ : Ortalama

SS: Standart sapma

Araştırmaya dahil edilen hastaların cilt kültürü sonuçlarının dağılımı Tablo III'de gösterilmiştir. Hastaların \%95.5'inde enjeksiyon öncesi, \%66.7'sinde ise enjeksiyon sonrası enjeksiyon bölgesinde üreme olduğu saptand1. Enjeksiyon öncesi enjeksiyon bölgesindeki $\mathrm{cm}^{2}$ başına ortalama CFU $60.13 \pm 51.65$, \%70'lik etil alkol kullandıktan sonraki ortalama CFU $15.98 \pm 25.27$ olarak belirlendi ve bu istatistiksel olarak anlamlı ölçüde yüksek bulundu ( $\mathrm{p}=0.000)$.

Tablo III. Hastaların Cilt Kültürü Sonuçlarının Dağ1limi

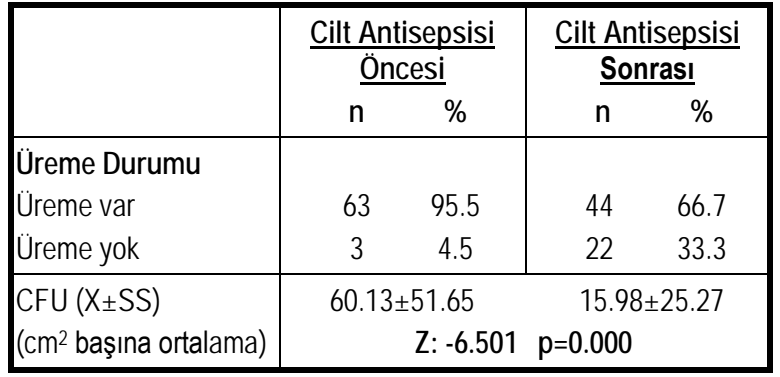

CFU: Colony Forming Unit

$\mathrm{X}$ : Ortalama

SS: Standart sapma

Z: Wilcoxon T testi

\section{Tartışma ve Sonuç}

Subkutan insülin enjeksiyon uygulamalarında standart bir uygulama basamağı olarak bilinen deri antisepsisinin gerekliliği günümüzde tartışmalı bir konu haline gelmiştir. Bu doğrultuda; insülin enjeksiyonu öncesi enjeksiyon bölgesindeki mikrobiyal yük inceleyerek deri antisepsisi için \%70’lik etil alkol kullanımının gerekli olup olmadığını değerlendirmeyi amaçladığ1mız çalışma sonucunda; hastaların \%95.5'inde enjeksiyon öncesi, \%66.7'sinde ise enjeksiyon sonrası enjeksiyon bölgesinde üreme olduğunu saptadık. Ayrıca enjeksiyon öncesi enjeksiyon bölgesi üzerindeki $\mathrm{cm}^{2}$ başına ortalama CFU değerinin, \%70'lik etil alkol kullandıktan sonraki ortalama CFU değerinden anlamlı derecede yüksek olduğu sonucuna ulaştık. Dan 


\section{Yılmaz, ark.}

(1969) altı yıl boyunca süren çalışmasında; 5000 enjeksiyon uygulamasını herhangi bir antiseptik madde ile deri hazırlığ yapmadan yapmış ve uygulama sonrası hastalarda herhangi bir lokal ya da sistemik enfeksiyonun görülmediği bildirmiştir ${ }^{25}$. Ayrıca, çalışma sonrasında enjeksiyon öncesi rutin deri hazırlığının istenmeyen yan etkilere neden olabileceğini ve hastanın kendi florasındaki mikroorganizmaları temizlemenin enfeksiyon riskini azaltmada yararlı bir etkisinin olmadığını açıklamıştır ${ }^{18,25}$. Yakın bir zamanda; Khawaja ve arkadaşları (2013) subkutan, intradermal ve intramüsküler enjeksiyonu öncesi \%70’lik etil alkol ile yapılan ve hiç yapılmayan cilt hazırlığı öncesinde; hastaların enjeksiyon bölgesinden alınan bakteri yüzdesini ve enjeksiyona bağlı gelişen lokal enfeksiyon bulgularını karşılaştırdıkları yarı deneysel bir çalışma yürütmüşlerdir. Çalışma sonunda; \%70'lik etil alkol ile yapılan deri antisepsisinin enjeksiyon bölgesindeki bakteri oranını \%47 oranında azalttığını, fakat enjeksiyona bağlı gelişen ödem, kızarıklık, ağrı gibi lokal enfeksiyon bulgularının görülmesi açısından aradaki farkın anlamlı olmadığını belirtmişlerdir ${ }^{26}$. Ayrıca çalışmada enjeksiyonlardan önce \%70’lik alkol ile yapılan deri antisepsisinin gereksiz olduğunu ve enfeksiyonu önlemede bir değer taşımadığını vurgulamışlardır. Konuyla ilgili yapılan farklı çalışma sonuçları incelendiğinde de çalışma sonucumuzun literatürle benzer olmadığını gördük ${ }^{8-13}$. Bu farklılığın çalışmanın yapıldığı kliniğin şartları, klinikte görev yapan sağlık personelin tıbbi bakım uygulama davranışları ve araştırma kapsamına alınan hastaların yaş, cinsiyet, öz bakım alışkanlıkları vb. gibi cilt üzerindeki mikroorganizma yoğunluğunu etkileyebilecek özelliklerden kaynaklandığ düşünülmektedir.

Diğer yandan, DSÖ açıklamasına ve literatürdeki çalışma verilerine göre subkutan enjeksiyonlardan önce eğer \%70'lik etil alkol ile deri antisepsisi gerekiyorsa; enjeksiyon bölgesinin tek kullanımlık pamuk çubukla 30 saniye boyunca silinmesi ve bakterilerin aktif hale getirilmemesi için 30 saniye daha kurumaya bırakılması önerilmektedir ${ }^{2,19,23,24,26,33}$. Yaptı̆̆ımız çalışmanın veri toplama aşamasında, bu öneriler gözardı edilmemiştir.

$\mathrm{Bu}$ araştırma sonucunda; Endokrinoloji ve Metabolizma Hastalıkları Kliniğinde Tip 1 DM tanısı ile yatan hastalara insülin enjeksiyonu öncesi cilt antisepsisinin gerekli olduğu kanısına varıldı. Araştırmanın bazı sınırlılıkları mevcuttur. Araştırmanın tek bir klinikte yürütülmesi, kontrol grubunun olmaması, sadece Tip 1 DM tanılı ve belirli sayıdaki hastaların araştırma kapsamına alınması araştırmanın sınırlılıkları içerisindedir. Araştırmanın bir diğer önemli sınırlılı̆̆ da; hastaların insülin enjeksiyon uygulaması sonrası enjeksiyon bölgesinde gelişebilecek lokal enfeksiyon bulguları (ödem, ekimoz, ağrı vb.) açısından takip edilmemesidir. $\mathrm{Bu}$ doğrultuda; araştırmanın farklı kliniklerde daha geniş bir örneklem üzerinde yürütül- mesi ve diğer enjeksiyon uygulamaları sonrası cilt kültürü sonuçlarını ve enfeksiyon bulgularını karşılaştıran çalışmalar yapılması önerilmektedir.

\section{Kaynaklar}

1. Ay F. İlaç Uygulamaları. İçinde: Ay F (ed). Sağlık uygulamalarında temel kavramlar ve beceriler. 5. Baskı. Ankara: Nobel Tıp Kitabevleri; 2013. 425-63.

2. Qamar M, Gillani SW, Sulaiman SAS. Skin preparation knowledge, attitudes and practices among the healthcare professionals in compliance with the World Health Organization (WHO) guidelines. Journal of Clinical and Diagnostic Research 2012;6(6):1041-6

3. Büyükyılmaz F, Çulha Y, Karaman A. Subkütan ilaç enjeksiyonlarında komplikasyonların önlenmesine ilişkin güvenli uygulama önerileri. G.O.P. Taksim E.A.H. JAREN 2018;4(2):108-11.

4. Rushing J. How to administer a subcutaneous injection. Nursing 2004;34(6):32.

5. Hunter J. Subcutaneous injection technique. Nurs Stand 2008;22(21):41-4

6. Kara D, Uzelli D. Güvenli subkutan enjeksiyon uygulamasına ilişkin literatür incelemesi. Sağlıkla Hemşirelik Dergisi 2015;Mart Sayıs1:34-36.

7. Akdemir N, Birol L. İç hastalıkları ve hemşirelik bakımı. 2. Bask1. Ankara: Sistem Ofset; 2004.

8. Satman İ. Diyabetes mellitus epidemiyolojisi, İçinde: İmamoğlu Ş (ed). Diyabetes mellitus multidisipliner yaklaşımla tanı, tedavi ve izlem. 3. Baskı. İstanbul: İstanbul Medikal Yayıncılık; 1135.

9. Aslan Ü, Korkmaz M. Diyabetli bireylerin insülin uygulama bilgi-beceri düzeyleri: Doğru ve yanlıșlar. DEUHFED 2015;8(1):18-26.

10. Grassi G, Scuntero P, Trepiccioni R, Marubbi F, Strauss K. Optimizing insulin injection technique and its effect on blood glucose control. Journal of Clinical \& Translational Endocrinology 2014;1(4):145-50.

11. Okuyan B, Sağlam B, Emre E ve ark. Tip 2 Diyabet hastalar1nın tek kullanımlık insulin kalemi kullanımı ile ilgili bilgi ve tutumlarının değerlendirilmesi. Marmara Pharmaceutical Journal 2014;18(3):159-63.

12. Arda H. Diabetes Mellitusu Olan Bireylerin Kendi Kendine İnsülin Uygulama Hatalarının İncelenmesi (Yüksek Lisans Tezi). İzmir: Dokuz Eylül Üniversitesi; 2009.

13. Hauner H., Haastert B, Stockamp B. Prevalence of lipohypertrophy in insülintreated diabetic patients and predisposing factors. Experimental and Clinical Endocrinology Diabetes 1996;104:106-10.

14. Strauss K, Gols HD, Letondeur C, Matyjaszczyk M, Frid A. The second injection technique event. Practical Diabetes International 2002;19(1):17-21.

15. Partanen T, Rissanen A. İnsulin injection practices. Practicial Diabetes İnternational 2000;17(8):252-4.

16. Vardar B, Kızılc1 S. Incidence of lipohypertrophy in diabetic patients and a study of influencing factors. Diabetes Research and Clinical Practice 2007;77:231-6.

17. Gawand KS, Gawali UP, Kesari HV. A study to assess knowledge, attitude and practice concerning insulin use in adults patients with diabetes mellitus in tertiary care centre. Indian J Med Res Pharm Sci 2016;3:52-6.

18. Güneş Ü. Hemşirelikte kanıta dayalı uygulama sürecinin adımları. Uluslararası Hakemli Hemşirelik Araştırmaları Dergisi 2017;9:171-87. 


\section{İnsülin Enjeksiyon Bölgesinin Mikrobiyal Yükü}

19. The World Health Organization guidelines best practice for injections and the related procedure toolkit, 2010. Erişim Tarihi: Eylül 2018, Erişim Adresi: http://apps.who.int/iris/bitstream/handle/10665/44298/9789241 599252_eng.pdf;jsessionid=BD7EF1D8942A8CE4E263D67B7 DB71296?sequence $=1$.

20. Hutin Y, Hauri A, Chiarello L et al. Best infection control practices for intradermal, subcutaneous, and intramuscular needle injections. Bulletin of the World Health Organization 2003;81(7):491-500.

21. İnsülin /GLP 1 kullananlar için enjeksiyon rehberi. Erişim Tarihi; Eylül 2017, Erișim Adresi http://www.tdhd.org/pdf/insulin_GLP_1_kullananlar_icin_enje ksiyon_rehberi.pdf.

22. Fleming DR, Jacober SJ, Vandenberg MA, Fitzgerald JT, Grunberger G. The safety of injecting insulin through clothing. Diabetes Care 1997;20(3):244-7

23. McCarthy JA, Covarrubias B, Sink P. Is the traditional alcoho wipe necessary before an insulin injection? Dogma disputed. Diabetes Care 1993;16(1):402.

24. Tandon N, Kalra S, Balhara YPS et al. Forum for injection technique and therapy expert recommendations, India: The Indian recommendations for best practice in insulin injection technique, 2017. Indian J Endocr Metab 2017;21:600-17.

25. Dann TC. Routine skin preparation before giving an injection: an unnecessary procedure. Lancet 1969;2:96-8.

26. Khawaja RA, Sikandar R, Qureshi R, Jareno RJM. (2013). Routine Skin Preparation with 70\% Isopropyl Alcohol Swab: Is it Necessary before an Injection? Quasi Study. JLUMHS 12(2):109-14.

27. Kuzu N. Subkütan heparin enjeksiyonu: Ekimoz, hematom ve ağrı gelişimi nasıl önlenir? Cumhuriyet Üniversitesi Hemşirelik Yüksekokulu Dergisi 1999;3(2):40-6.

28. Khawaja RA. The knowledge, attitude and practices towards a routine skin preparation before giving an injection, among physicians, nurses and patients in a teaching hospital of Saudi Arabia. World Family Medicine Journal March 2010;8.

29. Heise T, Nosek L, Dellweg S et al. Impact of injection speed and volume on perceived pain during subcutaneous injections into the abdomen and thigh: a single-centre, randomized controlled trial. Diabetes, Obesity and Metabolism 2014; April 11, doi: 10.1111/dom.12304.

30. Pourghaznein T, Azimi AV, Jafarabadi MA. The effect of injection duration and injection site on pain and bruising of subcutaneous injection of heparin. Journal of Clinical Nursing 2014;23(7-8):1105-13.

31. Sabuncu N, Alpar ŞE, Karabacak Ü ve ark. Hemşirelik esasları temel beceriler rehberi. 2. Baskı. İstanbul: İstanbul Medikal Yayıncılık; 2015.

32. Polat HT, Akpınar RB. İki farklı materyalle tespit edilen periferik venöz kateterlerin mikrobiyolojik kolonizasyon açısından karşılaştırılması. Gümüşhane Üniversitesi Sağlık Bilimleri Dergisi 2014;3(2):749-60.

33. Gorman CK. Good hygiene versus alcohol swabs before insülin injections. Diabetes Care 1993;16:960-1. 
